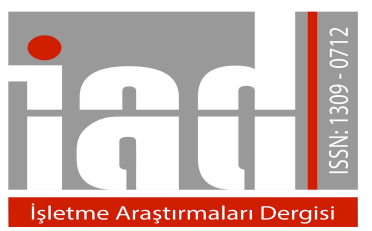

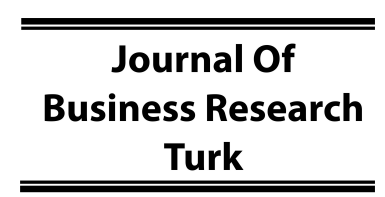

www.isarder.org

\title{
Büyük ve Orta Boy İşletmeler için Finansal Raporlama Standardı ile TMS/TFRS Karşılaştırması
}

\author{
A Comparison of Financial Reporting Standard for Large and Medium \\ Sized Entities and TAS/TFRS
}

\author{
Aziz DOĞAN \\ Kamu Gözetimi Muhasebe ve Denetim Standartları Kurulu Üyesi \\ orcid.org/0000-0002-6035-9379 \\ aziz_dogan@hotmail.com \\ $\ddot{O}_{z e t}$
}

Türkiye Muhasebe Standartları (TMS) ve Finansal Raporlama Standartlarinı (TFRS) uygulayan kamu yararını ilgilendiren kuruluşlar (KAYİK'ler) dışında bağımsız denetime tabi diğer işletmelerin münferit ve konsolide finansal tablolarının hazırlanmasında uygulanacak olan Büyük ve Orta Boy Işsletmeler için Finansal Raporlama Standardı (BOBI FRS)1 Ocak 2018 tarihi ve sonrasinda başlayan hesap dönemlerinde uygulanmak üzere, 29 Temmuz 2017 tarihinde Resmi Gazete'de yayımlanarak yürürlüğe girmiştir. Bu çalışmanın amacı, gerçeğe uygun, ihtiyaca uygun ve karşılaştırllabilir bilgi sağlamak amacılla hazırlanan BOBİ FRS'nin yayımlanma gerekçeleri ile genel özelliklerini incelemek ve açıklamak ve BOBI FRS hükümlerini TMS/TFRS'ler ile karşılaştırmaktır. TMS/TFRS'ler ile karşılaşıtırıldı̆̆ında, BOBI FRS'nin bazı yönleriyle benzerlik arz etmekle birlikte, genel olarak daha basitleştirilmiş hükümler içerdiği sonucuna varılmıştır.

Anahtar kelimeler: Büyük ve Orta Boy Işsletmeler için Finansal Raporlama Standard,, BOBI FRS, TMS, TFRS.

\begin{abstract}
Financial Reporting Standard for Large and Medium Size Entities (FRS for $L M E s)$ to be applied in preparation of individual and consolidated financial statements of the entities, subject to audit, other than public interest entities (PIEs) implementing Turkish Accounting Standards (TAS) and Financial Reporting Standards (TFRS), was published in Official Gazette on 29 July 2017, effective for periods beginning on or after 1st January 2018. The objective of this study is to examine and explain the rationale behind the issuance and the general features of FRS for LMEs issued in order to provide fair, relevant and comparable information, and make a comparison between the requirements of FRS for LMEs and TAS/TFRS. It is concluded that FRS for LMEs has commonly more simplified requirements even though it is similar in some ways compared to TAS/TFRS.
\end{abstract}

Keywords: Financial Reporting Standard for Large and Medium Size Entities, FRS for LMES, TAS, TFRS. 


\section{GİRIŞ}

Türkiye Muhasebe Standartları (TMS) ve Türkiye Finansal Raporlama Standartlarını (TFRS) ve yorumlarını zorunlu olarak uygulayan Kamu Yararını İlgilendiren Kuruluşlar (KAYİK) ile gönüllü olarak uygulayan diğer işletmelerin dışında bağımsız denetime tabi tüm işletmelerin 1 Ocak 2018 tarihinde ve sonrasında başlayan hesap dönemlerinde Büyük ve Orta Boy İşletmeler için Finansal Raporlama Standardı'nı (BOBİ FRS), uygulamaları gerekmektedir

Diğer bir deyişle, BOBİ FRS halka açık olmayan ve kamuya hesap verme yükümlülüğü bulunmayan işletmeler tarafından uygulanacaktır.

Kısaca KAYİK olarak adlandırılan halka açık şirketler, bankalar, sigorta, reasürans ve emeklilik şirketleri, faktoring şirketleri, finansman şirketleri, finansal kiralama şirketleri, varlık yönetim şirketleri, emeklilik fonları, ihraççılar ve sermaye piyasası kurumları ${ }^{1}$ önemli ölçüde kamuoyunu ilgilendirmekte ve bunların kamuya hesap verme yükümlülükleri bulunmaktadır.

Dolayısıyla BOBİ FRS'nin uygulanabilmesi için işletmenin büyüklüğü yanında işletmenin önemli ölçüde kamuoyunu ilgilendirmesi ve kamuya hesap verme yükümlülüğü bulunması, yani KAYİK olup olmadığı da dikkate alınmaktadır.

KAYİK'lerin uygulamak zorunda oldukları TMS/TFRS'lere uygun finansal tabloların hazırlanmasının karmaşık ve uzmanlık bilgisi gerektirmesi ve maliyetli olması nedeniyle, TMS/TFRS'lere göre basitleştirilmiş muhasebe ilkeleri içeren ve finansal tablolarda gerçeğe uygun sunum sağlayan BOBİ FRS hazırlanmıştır. BOBİ FRS finansal tablo kullanıcılarının gerçeğe ve ihtiyaca uygun, karşılaştırılabilir finansal bilgi ihtiyaçlarına cevap verirken, finansal tablo hazırlayanlar açısından da maliyet ve fayda arasında bir denge sağlamaktadır.

$\mathrm{Bu}$ çalışmada önce BOBİ FRS'nin hazırlanma gerekçeleri ve genel özellikleri hakkında bilgi verildikten sonra BOBİ FRS ile TMS/TFRS'ler arasındaki önemli benzerlik ve farklılıklara değinmek suretiyle genel bir karşılaştırma yapılacaktır.

\section{BOBİ FRS'NIN HAZIRLANMA GEREKÇESİ VE AŞAMALARI}

6102 sayılı Türk Ticaret Kanununun (TTK) 88 inci ve Geçici 1 inci maddeleri uyarınca gerçek ve tüzel kişi tacirlerin münferit ve konsolide finansal tablolarını hazırlarken KGK tarafından belirlenen ve yayımlanan Türkiye Muhasebe Standartlarını (TMS) uygulamaları öngörülmüştür. Ayrıca 88 inci maddede, değişik işletme büyüklükleri ve sektörler için özel standartlar ve düzenlemeler belirleme konusunda KGK yetkili kılınmış olup, söz konusu standart ve düzenlemelerin TMS'nin bir cüzü olarak addedileceği ifade edilmiştir.

Söz konusu TTK hükümleri kapsamında, 26/08/2014 tarihli ve 29100 say1lı Resmi Gazetede yayımlanan KGK Kurul Kararıyla, KAYİK'lerin münferit ve konsolide finansal tablolarının hazırlanmasında TMS/TFRS uygulanması zorunlu kılınmıştır. Bu karar uyarınca bağımsız denetime tabi olup TMS/TFRS uygulamayan işletmelerin ise KGK tarafından yeni bir düzenleme yapılıncaya kadar yürürlükteki mevzuat olan MSUGT'ları uygulayarak finansal tablolarını hazırlaması öngörülmüştür.

\footnotetext{
${ }^{1} 660$ Sayıl1 Kanun Hükmünde Kararname, Resmi Gazete, 02.11.2011/28103, Madde: 2/ğg.
} 
MSUGT'larda bazı kalemlere ilişkin değerleme hükümlerine yer verilmemiş olması, değerleme hükümlerinin ihtiyari bırakılmış olması veya öngörülen değerleme hükümlerinin uygulanma şekline ilişkin esasların açıklanmamış olması, ayrıca kıdem tazminatı, amortisman, reeskont gibi çoğu uygulamanın ihtiyari olması ve finansal tabloların amacının işletmenin vergi matrahına ulaşmak olarak görülmesi sebebiyle MSUGT'lara göre hazırlanan finansal tablolar bağımsız denetime uygun bir kıstas teşkil etmemekte ve bağımsız denetimin kalitesini ve güvenilirliğini azaltmaktaydı. Ayrıca MSUGT'lara göre hazırlanan finansal tabloların gerçeğe uygun, ihtiyaca uygun ve karşılaştırılabilir sunum sağlama amacından uzaklaştığ1 görülmüştür.

Avrupa Birliği (AB)'nde, payları borsada işlem gören işletmelerin konsolide finansal tablolarını Uluslararas1 Finansal Raporlama Standartlarına (IFRS) uygun olarak hazırlamaları zorunlu olup, diğer işletmelerin finansal tablolarını IFRS'e uygun olarak hazırlayıp hazırlamamaları ise üye ülke tercihine bırakılmıştır. IFRS uygulamayan işletmeler finansal tablolarını, 1 Ocak 2016 tarihinden itibaren IFRS'e göre basitleştirilmiş muhasebe ilkeleri içeren 2013/34/EU sayılı Direktife (Muhasebe Direktifi) uygun olarak hazırlamaktadır.

Diğer taraftan, AB müktesebatının 6 no'lu şirketler hukuku faslının alt başlığı olan "Muhasebe ve Denetim" alanındaki AB düzenlemelerine uyumun sağlanması amacıyla AB Muhasebe Direktifiyle uyumlu bir mevzuatın hazırlanması gerekmiştir.

Ülkemizde bağımsız denetime tabi olup TMS/TFRS uygulamayan işletmelerin uyguladığı yürürlükteki mevzuat hükümlerinin söz konusu AB Direktifi hükümleriyle uyumlu olmaması ve temel muhasebe esasları açısından uygulamada çeşitli eksikliklerinin bulunması nedeniyle, KGK tarafindan 2014 yılında MSUGT'lara ek olarak "TMS'leri Uygulamayan Şirketlerin Finansal Tablolarının Hazırlanmasında Uygulanacak İlave Hususlar" yayımlanmıştır. ${ }^{2}$ Söz konusu "İlave Hususlar", geçici bir düzenleme olarak yayımlanmış ve bu düzenlemeyle MSUGT'larda yer almayan veya ihtiyari bırakılan hususlarla ilgili temel kurallar (amortisman ve kıdem tazminatı karşılığ1 ayrılmasının zorunlu hale gelmesi gibi) getirilmesi amaçlanmıştır.

Bu nedenle, kalıcı bir çözüm olması amacıyla KGK tarafından 2014 yılında yerel finansal raporlama çerçevesi (YFRÇ) hazırlık çalışmaları başlatılmıştır. Bu çalışmalar kapsamında bir çalışma ve danışma komisyonu oluşturulmuş olup, bu komisyonda yer alan gerek kamu kurum ve kuruluşları gerekse mesleki ve sivil toplum kuruluşları temsilcileri ile akademisyenler çalışmalara katkı sağlamıştır. Bu çalışmalar sonucunda ortaya çıkan taslak metin 2015 yılı Kasım ayında kamuoyu görüşüne açılmıştır.

Daha sonra düzenlenen çalıştaylarda ${ }^{3}$ değerlendirilen taslak YFRÇ metni, paydaşların görüşleri de dikkate alınarak, KGK tarafından BOBİ FRS adıyla, 1 Ocak 2018 tarihi ve sonrasında başlayan hesap dönemlerinde uygulanmak üzere, 29 Temmuz 2017 tarihli Mükerrer Resmi Gazete'de yayımlanarak yürürlüğe girmiştir.

KGK verilerine göre, 2016 yılında bağımsız denetim sözleşmesi imzalayan 6.250 şirket bulunmaktadır. $\mathrm{Bu}$ şirketlerden KAYİK tanımını karşılayan 1.550 şirket

\footnotetext{
${ }^{2}$ 29.12.2014 tarihli ve 41 sayılı KGK Kurul Kararı, Resmi Gazete, Sayı: 29221, 30.12.2014.

${ }^{3}$ YFRÇ Taslağının Değerlendirilmesi Çalıştayı, Aralık 2015 (Başkent Üniversitesi - MÖDAV) ve YFRÇ Taslağı Uygulama Çalıştayı ve YFRÇ İhtiyacı ve Uygulama Üzerine Değerlendirme Paneli, Şubat 2017 (Marmara Üniversitesi ve İSMMMO).
} 
TMS/TFRS uygulamakta olup, kalan 4.700 şirket 1 Ocak 2018'den itibaren BOBİ FRS'yi uygulayacaktır.

BOBİ FRS'nin yürürlüğe girmesiyle birlikte bağımsız denetime tabi olup TMS/TFRS uygulamayan 4.700 civarındaki şirket sayısının ilerleyen yıllarda bağımsız denetim kapsamının genişletilmesiyle birlikte kademeli olarak artacağ öngörülmektedir.

\section{BOBİ FRS'NİN GENEL ÖZELLİKLERİ}

BOBİ FRS, bağımsız denetime tabi olup TMS/TFRS uygulamayan işletmelerde MSUGT'lar ve "İlave Hususlar"1n yerini almıştır. Diğer bir ifadeyle, söz konusu işletmelerin TTK uyarınca genel kurullarına sunulacak finansal tablolarının hazırlanmasında esas alınacak finansal raporlama çerçevesi BOBİ FRS olacaktır.

BOBİ FRS, bağımsız denetime kıstas teşkil edecek bir finansal raporlama çerçevesinin taşıması gereken özellikleri karşılamaktadır. Bunun yanı sıra, BOBİ FRS'de, AB Direktifindeki istisnalardan faydalanılarak orta ölçekli işletmelerin, büyük işletmelerin tabi olduğu bazı yükümlülüklerden muaf tutulması öngörülmüştür.

Uluslararası muhasebe ve finansal raporlama uygulamalarıyla ve $A B$ düzenlemeleriyle uyumlu olan BOBİ FRS, sade ve anlaşılır bir dille kaleme alınmış olup, işletmelerin genel olarak karşılaşabileceği tüm muhasebe işlemlerine ilişkin muhasebe esaslarını belirlemektedir. Bu yönüyle başka bir standart setine ihtiyaç duyulmadan finansal tabloların hazırlanmasına imkân vermektedir. Ayrıca, bağımsız denetime kıstas teşkil edecek "kabul edilebilir" bir finansal raporlama çerçevesidir.

27 bölümden oluşan BOBİ FRS'nin her bir bölümü, işletmeler ile finansal tablo kullanıcılarının ihtiyaç duydukları bilgiye referansta bulunabilmelerini sağlamak amacıyla numaralandırılmış paragraflar içermekte olup, terimler sözlüğüne ve ekinde konsolide olmayan ve konsolide finansal tablo örneklerine yer verilmiştir. Terimler sözlüğünde yer alan terimler her bölümde ilk kullanıldıkları yerde koyu yazılarak kullanıcılar için kolaylık sağlanmıştır.

Diğer taraftan, kabul edilebilir bir finansal raporlama çerçevesinin gerektirdiği tüm özellikleri taşıyan BOBİ FRS; AB Muhasebe Direktifindeki "önce küçükleri düşün" yaklaşımından hareketle, orta büyüklükteki işletmeler için genel olarak maliyet esaslı bir finansal raporlama öngörmüş, büyük işletmelere ise ilâve yükümlülükler getirmiştir.

\section{BOBİ FRS İLE TMS/TFRS KARŞILAŞTIRMASI}

\subsection{Kavramsal Çerçeve ve Finansal Tablolar}

BOBİ FRS'nin 1 inci bölümü "Kavramsal Çerçeve ve Finansal Tablolar" konusunu düzenlerken, finansal tablolarla ilgili olan "Nakit Akış Tablosu" 2 nci bölümde, "Ara Dönem Finansal Raporlama" 24 üncü bölümde, "Dipnotlar" ise 26 nc1 bölümde yer almıştır.

BOBİ FRS'de genel finansal raporlama ilkeleri, işletmenin sürekliliği, tahakkuk esası, ihtiyatlılık, önemlilik, mahsup yasağı, raporlamanın sıklığı, karşılaştırmalı bilgi,

\footnotetext{
${ }^{4}$ KGK (Kamu Gözetimi Muhasebe ve Denetim Standartları Kurumu), Basın Duyurusu, 30.7.2017.
} 
sunumda tutarlılık olarak açıklanmıştır. Söz konusu ilkeler açısından bakıldığında, ihtiyatlılık ilkesi hariç BOBİ FRS, TMS 1 ile uyumludur.

Finansal tablolarla ilgili hükümlere baktığımızda, BOBİ FRS'de yer alan finansal durum tablosu, kâr veya zarar tablosu, nakit akış tablosu, özkaynak değişim tablosu ve dipnotlar, TMS 1 ile uyumludur. Ancak, kâr veya zarar tablosunun sunumunda TMS 1'de yer alan diğer kapsamlı gelirin sunumuna BOBİ FRS'de yer verilmemiştir.

Diğer taraftan, kâr veya zarar tablosunun hazırlanmasında BOBİ FRS'de, fonksiyon esası kullanılmakta iken, TMS 1'de fonksiyon esası ve çeşit esası kullanılmaktadır.

Nakit akış tablosunun sunumu açısından bakıldığında, BOBİ FRS'de nakit akışları sınıflandırılarak (esas/yatırım/finansman faaliyetleri) sunulduğundan, TMS 1 ile uyum arz etmektedir.

\subsection{Geçiş Hükümleri (İlk Uygulama)}

TFRS 1 kapsamında TFRS'lerin ilk kez uygulandığı finansal tablolar, sunulan tüm tablolar için karşılaştırmalı bilgiye yer verecek şekilde, en az üç finansal durum tablosunu, iki kapsamlı gelir tablosunu, iki bireysel gelir tablosunu (sunulması durumunda), iki nakit akış tablosunu, iki özkaynak değişim tablosunu ve ilgili dipnotları içermektedir. Ancak BOBİ FRS'yi ilk kez uygulayan bir işletmenin geçmiş dönem veya dönemlere ait karşılaştırmalı finansal tablolarını hazırlaması zorunlu tutulmamakta; bu muafiyetten yararlanan işletmelerin sadece cari hesap dönemine ait finansal tablolarını ve cari hesap döneminin başlangıcına ait finansal durum tablosunu (açılış finansal durum tablosunu) düzenlemesi öngörülmektedir.

\subsection{Muhasebe Politikaları, Tahminler ve Yanlışlıklar}

BOBİ FRS'de yer alan, muhasebe politikasında bir değişikliğe gidilmesi durumunda politika değişikliğinin geriye dönük olarak uygulanmasına ilişkin hüküm TMS 8 ile uyumluluk arz etmektedir.

Aynı şekilde, muhasebe tahminlerinde yapılan değişikliklerin ileriye yönelik olarak uygulanması ve yanlışlıkların geriye dönük düzeltilmesi de TMS 8 ile uyumludur.

\subsection{Raporlama Döneminden Sonraki Olaylar}

BOBİ FRS'de yer alan, raporlama döneminden sonraki düzeltme gerektiren olayların etkisinin yansıtılması amacıyla ilgili dipnotlar dâhil raporlama dönemine ait finansal tablolarda yer alan tutarların düzeltilmesine ve raporlama döneminden sonraki düzeltme gerektirmeyen olayların etkisinin yansıtılması amaciyla raporlama dönemine ait finansal tablolarda yer alan tutarlarda herhangi bir değişiklik yapılmayacağ 1 ancak önemli nitelikte olanların dipnotlarda açıklanacağına ilişkin hükümler TMS 10 ile uyumludur.

\subsection{Hasilat}

Hasılatın kayda alınma ölçütleri, BOBİ FRS'de ekonomik faydaların işletmeye girmesinin muhtemel olması ve söz konusu faydaların güvenilir biçimde ölçülebilmesi olarak belirlenirken, TMS/TFRS'de edim yükümlülüğünün yerine getirilmesi (bir anda ya da zamana yayılı bir şekilde) olarak belirlenmiştir. 
Hasılatın ölçümü, BOBİ FRS'de taraflar arasında yapılan anlaşma kapsamında, satış iskontoları (kasa ve miktar iskontoları) da düşüldükten sonra, alınan veya alınması beklenen bedel esas alınarak yapılırken, TMS 18'de işlem bedeli (değişken/sabit) esas alınarak yapılmaktadır.

BOBİ FRS'ye göre, hasılat bedelinin, bir yıldan daha uzun bir vadede tahsil edilmesinin öngörülmesi durumunda vade farkı ayrıştırılması gerekirken, TMS 18'e göre tüm vade farklarının ayrıştırılması gerekir.

Hizmet sunumunda ilgili hasılat tutarı, BOBİ FRS'ye göre işlemin raporlama dönemi sonu itibarıyla tamamlanma düzeyi dikkate alınarak kayda alınırken, TMS 18'e göre edim yükümlülüğü yerine getirildiğinde (bir anda ya da zamana yayılı bir şekilde) kayda alınmaktadır.

BOBİ FRS'ye göre, inşa sözleşmelerine ilişkin hasılat ve maliyetler, raporlama dönemi sonu itibarıyla sözleşme kapsamındaki faaliyetin tamamlanma düzeyi dikkate alınarak kâr veya zarara yansitılırken, TMS11'e göre edim yükümlülüğü yerine getirildikçe zamana yayılı olarak muhasebeleştirilir.

Faiz ise hem BOBİ FRS hem de TMS 18'e göre, etkin faiz yöntemiyle hesaplanarak muhasebeleştirilir.

\subsection{Stoklar}

BOBİ FRS'de, bir yıl veya daha kısa vadeli bir ödeme karşılığında satın alınan stoklar vade farkı ayrıştırılmaksızın, bir yıldan uzun vadeli bir ödeme karşılığında satın alınan stoklar ise vade farkı ayrıştırılarak ölçülmektedir. TMS 2 kapsamında ise vadeli olarak alınmış bir stoka ilişkin vade farkı, stokun maliyetine dâhil edilmemekte, yani bütün vade farkları ayrıştırılmaktadır.

BOBİ FRS kapsamında tam maliyet yöntemi veya normal maliyet yöntemlerinden biri kullanılabilirken, TMS 2'de sabit üretim giderlerinin normal maliyet yöntemi kullanılarak dağıtılması öngörülmektedir.

BOBİ FRS'de, üretilmesi normal şartlar altında bir yıldan daha uzun süren stoklar için katlanılan borçlanma maliyetlerinin satışa hazır hale geldiği tarihe kadar stokların maliyetine dâhil edileceği; TMS 23'de özellikli varlık (satışa ve kullanıma hazır hale gelmesi uzun süreyi gerektiren varlık) niteliği taşıyan stoklara ilişkin borçlanma maliyetlerinin stokların maliyetine dâhil edileleceği belirtilmekte olup, her iki hüküm birbiriyle uyumludur.

Stokların dönem sonu ölçümü, BOBİ FRS ve TMS'de benzerlik arz etmektedir. Yani stokların dönem sonu ölçümü, maliyet bedeli ile net gerçekleşebilir değerden düşük olanı üzerinden yapılmaktadır.

BOBİ FRS'ye göre, stokların değer düşüklüğüne uğraması durumunda, stokların defter değeri net gerçekleşebilir değerine indirilir; bu indirim tutarı, değer düşüklüğü zararını oluşturur ve Kâr veya Zarar Tablosunda "Satışların Maliyeti" kalemine yansitılır. Bu hüküm TMS 2'ye uygundur.

\subsection{Tarımsal Faaliyetler}

BOBİ FRS kapsamında canlı varlıkların ölçümünde maliyet yöntemi veya gerçeğe uygun değer yöntemlerinden biri kullanılabilmektedir. TMS 41'de ise canlı varlıklar 
gerçeğe uygun değerin güvenilir olarak ölçülemediği durumlar hariç olmak üzere, gerçeğe uygun değerlerinden satış maliyetleri düşülmek suretiyle ölçülmektedir.

İşletmenin tarımsal ürünleri, hasat zamanında satış maliyetleri düşülmüş gerçeğe uygun değeri üzerinden ölçülür. Tarımsal ürünlerin ölçümü TMS 41 ile uyumludur.

Canlı varlıkların sunumuna bakıldığında; canlı varlıkların Finansal Durum Tablosunda, dönen varlık ya da duran varlık sınıfı altında yer alan "Canlı Varlıklar" kaleminde ayrı bir şekilde sunulduğu görülmekte olup, TMS 41 ile uyumludur.

\subsection{Maden Kaynaklarının Aranması ve Değerlendirilmesi}

Hem BOBİ FRS hem de TFRS 6'ya göre arama ve değerlendirme varlıklarının ilk ölçümü maliyet bedeli ile yapılmaktadır. Sonraki ölçüm ise; BOBİ FRS'ye göre maliyet bedelinden amortisman (veya itfa) ve varsa değer düşüklüğü zararı düşülmüş tutar üzerinden (maliyet modeli) yapılırken, TFRS 6'ya göre maliyet modeli ya da yeniden değerleme modeli uygulanarak yapılmaktadır.

Değer düşüklüğü açısından BOBİ FRS ve TFRS 6 uyumludur. Varlığın defter değerinin geri kazanılabilir tutarı aşabileceğini gösteren durum ve şartların mevcut olması halinde bu varlıklar değer düşüklügü açısından değerlendirilir.

\subsection{Finansal Araçlar ve Özkaynaklar}

BOBİ FRS'de vadesi bir yıl veya daha kısa olan alacaklar ve borçlar itibari değeri üzerinden, bir yıldan uzun olan alacaklar ve borçlar ise itfa edilmiş değeri üzerinden ölçülmektedir. TFRS 9 kapsamında alacak ve borçlar ise itfa edilmiş maliyetleri üzerinden ölçülmektedir.

BOBİ FRS'de finansal araçlar niteliklerine göre dört farklı sınıfta (alacaklar ve borçlar, borçlanma araçları, özkaynağa dayalı finansal varlıklar, diğer finansal araçlar) muhasebeleştirilmektedir. TFRS 9'da ise finansal araçların ölçümü finansal aracın nakit akış özellikleri ve işletmenin iş modeli dikkate alınarak üç farklı ölçüm sınıfında (itfa edilmiş maliyet, gerçeğe uygun değer değişimi diğer kapsamlı gelire yansıtılan veya gerçeğe uygun değer değişimi kâr veya zarara yansıtılan) muhasebeleştirilmektedir.

BOBİ FRS'de piyasada işlem gören özkaynak araçları piyasa değeri üzerinden, piyasada işlem görmeyenler ise maliyet değeri üzerinden ölçülmekteyken, TFRS 9 kapsamında özkaynak araçları, gerçeğe uygun değer üzerinden ölçülmektedir.

BOBİ FRS'de gözlemlenebilir kanıtların bulunması durumunda ticari alacaklara ilişkin değer düşüklüğü karşılığ 1 ayrılmaktadır. TFRS 9'da ise beklenen kredi zararı yaklaşımına göre değer düşüklüğü kayda alınmaktadır.

Hisse senedi yatırımlarının muhasebeleştirilmesinde, BOBİ FRS'ye göre, borsada işlem görenlerin gerçeğe uygun değerleri (piyasa değeri), borsada işlem görmeyenlerin ise maliyet bedelleri esas alınır. TFRS 9'da ise hisse senedi yatırımları gerçeğe uygun değerleri üzerinden ölçülmektedir.

Borçlanma aracı niteliğindeki menkul kıymet yatırımları ile banka kredileri ve ihraç edilen menkul kıymetler, BOBİ FRS'de itfa edilmiş değerleri üzerinden ölçülürken, TFRS 9'da itfa edilmiş maliyetleri üzerinden ölçülmektedir.

Türev araçları açısından bakıldığında ise BOBİ FRS ve TFRS 9 uyumlu görünmektedir. 


\subsection{0. İştiraklerdeki Yatırımlar}

İştirak; adi ortaklık gibi tüzel kişiliği olmayan işletmeler de dâhil olmak üzere, yatırım yapan işletmenin üzerinde önemli etkisinin bulunduğu, müşterek girişim veya bağlı ortaklık niteliğinde olmayan işletmedir. İştirak tanımında hem BOBİ FRS'de hem de TMS 28' de "önemli etkinin bulunması" kıstas olarak alınmıştır.

Hem BOBİ FRS hem de TMS 28'e göre iştiraklerdeki yatırımlar konsolide finansal tablolarda özkaynak yöntemi kullanılarak ölçülmektedir.

BOBİ FRS'ye göre münferit finansal tablolarda, iştiraklerdeki yatırımlar maliyet yöntemi veya özkaynak yöntemlerinden biri tercih edilerek ölçülürken, TMS 27 uyarınca, münferit finansal tablolarda, iştirakler maliyet yöntemi, gerçeğe uygun değer yöntemi veya özkaynak yöntemlerinden biri tercih edilerek, ölçülmektedir.

\subsection{Müşterek Girişimlerdeki Yatırımlar}

Müşterek kontrol, hem BOBİ FRS' de hem de TFRS 11'de bir anlaşma üzerindeki kontrolün sözleşmeye dayalı olarak paylaşılması olarak tanımlanmakta ve söz konusu kontrolün, ilgili faaliyetlere ilişkin kararların kontrolü paylaşan tarafların oy birliği ile mutabakatını gerektirdiği belirtilmektedir.

Hem BOBİ FRS hem de TMS 28'e göre iştiraklerdeki yatırımlar konsolide finansal tablolarda özkaynak yöntemi kullanılarak ölçülmektedir.

BOBİ FRS'ye göre münferit finansal tablolarda, bağl1 ortaklıklardaki, iştiraklerdeki ve müşterek girişimlerdeki yatırımlar maliyet yöntemi veya özkaynak yöntemlerinden biri tercih edilerek ölçülürken, TMS 27 uyarınca, münferit finansal tablolarda, bu yatırımlar maliyet yöntemi, gerçeğe uygun değer yöntemi veya özkaynak yöntemlerinden biri tercih edilerek, ölçülmektedir.

\subsection{Maddi Duran Varlıklar}

BOBİ FRS'ye göre, maddi duran varlıklar, sonraki ölçümlerinde birikmiş amortisman ve birikmiş değer düşüklüğü zararları indirilmek suretiyle maliyeti üzerinden veya yeniden değerlenmiş tutarı üzerinden değerlenir. Bu hüküm TMS 16 ile uyumludur.

BOBİ FRS kapsamında, bir yıl veya daha kısa vadeli bir ödeme karşılığında satın alınan maddi duran varlıklar vade farkı ayrıștırılmaksızın, bir yıldan uzun vadeli bir ödeme karşılığında satın alınan maddi duran varlıklar ise vade farkı ayrıştırılarak ölçülür. TMS 16'da ise vadeli olarak alınmış bir maddi duran varlığa ilişkin vade farkı, varlığın maliyetine dâhil edilmemektedir.

BOBİ FRS'de, inşası normal şartlar altında bir yıldan daha uzun süren maddi duran varlıklar için katlanılan borçlanma maliyetlerinin kullanıma hazır hale geldiği tarihe kadar maddi duran varlığın maliyetine dâhil edileceği; TMS 23'de özellikli varlık (satışa ve kullanıma hazır hale gelmesi uzun süreyi gerektiren varlık) niteliği taşıyan bir varlığa ilişkin borçlanma maliyetlerinin varlığın maliyetine dâhil edileleceği belirtilmekte olup, her iki hüküm birbiriyle uyumludur.

Hem BOBİ FRS hem de TMS 16'da maddi duran varlıklar için amortisman uygulaması zorunludur. 
Bir varlığın işletme tarafından beklenen kullanım süresini ya da işletme tarafından ilgili varlıktan elde edilmesi beklenen üretim veya kullanım miktarını ifade eden faydalı ömür, işletme tarafından gerçekçi tahminlere dayanılarak belirlenir, şeklindeki BOBİ FRS hükmü TMS 16 ile uyumludur.

Aynı şekilde, BOBİ FRS'de yer alan, amortismana tâbi tutarın, maddi duran varlığın maliyet bedelinden ya da yeniden değerleme sonrası bulunan tutarından kalıntı değerin indirilmesi suretiyle belirleneceğine ilişkin hüküm de TMS 16 ile uyumludur.

\subsection{Yatırım Amaçlı Gayrimenkuller}

BOBİ FRS'ye göre, yatırım amaçlı gayrimenkuller ilk kayda almada maliyet bedeliyle ölçülürken, ilk kayda almadan sonra (sonraki ölçüm) gerçeğe uygun değer yöntemi ya da maliyet yöntemi uygulanarak ölçülebilmektedir. Söz konusu hükümler TMS 40 ile uyumludur.

Ancak, BOBİ FRS'de maliyet bedeli üzerinden ölçülen yatırım amaçlı gayrimenkullerin gerçeğe uygun değerinin dipnotlarda sunulması öngörülmemekle birlikte, TMS 40 uyarınca maliyet yöntemi kullanılsa dahi dipnotlarda yatırım amaçlı gayrimenkulün gerçeğe uygun değerinin açıklanması gerekmektedir.

\subsection{Maddi Olmayan Duran Varlıklar}

Maddi olmayan duran varlıklar BOBİ FRS'ye göre, ilk kayda almadan sonra birikmiş itfa payları ve birikmiş değer düşüklüğü zararları düşülmek suretiyle maliyeti üzerinden ölçülür. TMS 38 uyarınca maddi olmayan duran varlıklar, maliyet modeli veya yeniden değerleme modeli kullanılarak ölçülebilmektedir.

BOBİ FRS uyarınca faydalı ömrü belirlenemeyen maddi olmayan duran varlıklar beş ile on y1l arasında itfa edilirken, TMS 38'de bu varlıklar itfaya tabi tutulmamaktadır.

Diğer taraftan faydalı ömrü sınırlı olan maddi olmayan duran varlıklar için, işletme tarafından gerçekçi tahminlere dayanılarak serbestçe belirlenen faydalı ömrü süresince belirlenen itfa payı ayrılması zorunludur, şeklindeki BOBİ FRS hükmü TMS 38 ile uyumludur.

Araştırma ve geliştirme giderleri ile ilgili olarak, BOBİ FRS'de yer alan, araştırma safhasında yapılan harcamalar aktifleştirilmez, gerçekleştiğinde gider olarak kâr veya zarara yansıtılır; geliştirme safhasında (bazı şartların karşılanması halinde) yapılan harcamalar maddi olmayan duran varlık olarak aktifleştirilir hükmü, TMS 38 ile uyumludur.

BOBİ FRS'de, oluşturulması normal şartlar altında bir yıldan daha uzun süren maddi olmayan duran varlıklar için katlanılan borçlanma maliyetlerinin kullanıma hazır hale geldiği tarihe kadar maddi olmayan duran varlı̆̆ın maliyetine dâhil edileceği; TMS 23 'de özellikli varlık (satışa ve kullanıma hazır hale gelmesi uzun süreyi gerektiren varlık) niteliği taşıyan bir varlığa ilişkin borçlanma maliyetlerinin varlığın maliyetine dâhil edileleceği belirtilmekte olup, her iki hüküm birbiriyle uyumludur.

\subsection{Kiralamalar}

Kiralamalara ilişkin olarak hem geleneksel kiralama hem de finansal kiralama açısından BOBİ FRS ile TMS 17 karşılaştıııldığında, uyumlu oldukları görülmektedir. 
Bir kiralama işleminin finansal kiralama veya geleneksel kiralama olarak sınıflandırılmasında kullanılacak kıstaslara ilişkin olarak BOBİ FRS ile TMS 17 örtüşmekle birlikte, BOBİ FRS'de daha somut hale getirilmiş kıstaslara yer verilmiştir.

\subsection{Devlet Teşvikleri}

BOBI FRS'de devlet teşviklerinin muhasebeleştirilmesinde tek seçenek olarak performans modeli sunulmakta, TMS 20'de ise devlet teşviklerinin muhasebeleştirilmesiyle ilgili gelir ve sermaye yaklaşımı olmak üzere iki seçenek sunulmaktadir.

\subsection{Borçlanma Maliyetleri}

BOBİ FRS'ye göre, üretilmesi, inşası ya da oluşturulması normal şartlar altında bir yıldan daha uzun süren stokların, maddi duran varlıkların, yatırım amaçlı gayrimenkullerin ve maddi olmayan duran varlıkların elde edilmesiyle doğrudan ilişkili olan borçlanma maliyetleri (örneğin bu varlıklar için kullanılan krediler nedeniyle katlanılan kur farkları dâhil finansman giderleri), söz konusu varlığın satışa veya kullanıma hazır hale getirildiği tarihe kadar, varlığın maliyetine dâhil edilir. Diğer tüm borçlanma maliyetleri ise oluştukları dönemde Kâr veya Zarar Tablosunun ilgili kaleminde kâr veya zarara yansitılır.

TMS 23 uyarınca özellikli varlık niteliği taşıyan bir varlığa ilişkin borçlanma maliyetleri varlığın maliyetine dâhil edilmektedir.

Aslında BOBİ FRS'deki uygulama ile TMS 23'deki uygulama uyumludur. Özellikli varlık, satışa ve kullanıma hazır hale gelmesi uzun süreyi gerektiren varlık olarak tanımlandığ 1 için ve uzun süre de bir yılı aşan süre olarak kabul edildiğinden BOBİ FRS ile uyumludur. Sadece BOBİ FRS'de "Özellikli Varlık" ifadesi kullanılmamış onun yerine "inşası ya da oluşturulması normal şartlar altında bir yıldan daha uzun süren.....” ifadesi kullanılmıştır.

\subsection{Varlıklarda Değer Düşüklüğü}

Bir varlığın defter değerinin geri kazanılabilir tutarından büyük olması durumunda değer düşüklüğü zararı oluşmaktadır. Varlıklarda değer düşüklüğüne ilişkin bu ölçüm TMS 36 ile uyumludur.

Şerefiye; BOBİ FRS'ye göre değer düşüklüğü testine tâbi tutulmazken, TMS 36 'ya göre değer düşüklüğü testine tabi tutulmaktadır.

BOBİ FRS'de yer alan, maliyet bedeliyle ölçülen varlıklara ilişkin değer düşüklüğü zararları kâr veya zarara yansıtılır hükmü de TMS 36 ile uyumludur.

\subsection{Karşılıklar, Şarta Bağlı Yükümlülükler ve Şarta Bağlı Varlıklar}

Hem BOBİ FRS hem de TMS 37'de karşılıkların kayda alma ölçütlerini sağladıklarında muhasebeleştirilmeleri öngörülmüştür.

TMS 37 kapsamında karşılıklar, yükümlülüğün yerine getirilmesi için gereken tutarın bugünkü değeri üzerinden hesaplanmaktadır. BOBİ FRS'de ise karşıllıların bugünkü değer üzerinden ölçümü isteğe bağlı olarak uygulanmaktadır. Ayrıca BOBİ FRS bugünkü değer yanında, bugünkü değer hesaplaması yapmadan karşılık tutarının yükümlülüğün yerine getirilmesi için yapılması beklenen harcama tutarı üzerinden hesaplanmasına da imkân vermektedir. 
Kıdem tazminatı karşılığı, TMS 19 kapsamında detaylı aktüeryal hesaplamalar yapılarak muhasebeleştirilirken, BOBİ FRS'ye göre, işletmenin iş gücü devir hızı ve önceki yıllarda gerçekleşen kıdem tazminatları gibi etkenler dikkate alınarak, çalışanların ilgili döneme ilişkin kıdeme esas ücreti üzerinden hesaplanan, cari dönemde ortaya çıkan kıdem tazminatı yükümlülük artışları giderleştirilir.

BOBİ FRS'ye göre, şarta bağlı varlık nedeniyle işletmeye ekonomik fayda girişinin olması muhtemelse (diğer bir ifadeyle gerçekleşme olasılığının, gerçekleşmeme olasılığından daha yüksek olması), dipnotlarda şarta bağlı varlığın niteliğine ilişkin kısa bir açıklama yapılır ve şarta bağlı varlığın muhtemel finansal etkisine ilişkin bilgi verilir.

Aynı şekilde, şarta bağlı yükümlülük nedeniyle işletmeden kaynak çıkışının olma ihtimali çok düşük değilse, dipnotlarda şarta bağlı yükümlülüğün niteliğine ilişkin kısa bir açıklama yapılır ve şarta bağlı yükümlülüğün muhtemel finansal etkisine ilişkin bilgi verilir.

Ancak hem şarta bağlı varlıklar hem de şarta bağlı yükümlülükler Finansal Durum Tablosunda gösterilmez. Bu hükümler TMS/TFRS ile benzerlik arz etmektedir.

\subsection{Yabancı Para Çevrim İşlemleri}

Yabancı para cinsinden işlemler ilk kayda alınırken, yabancı para birimindeki tutar işlem tarihindeki spot kur kullanılarak çevrilir.

Yabancı para cinsinden Finansal Durum Tablosu kalemlerinin dönem sonundaki ölçümleri, bunların parasal veya parasal olmayan kalem olmasına göre farklılık göstermektedir. Yabancı para cinsinden parasal kalemler, dönem sonundaki spot kur kullanılarak çevrilmekte; parasal olmayan kalemler ise, maliyet bedelleri üzerinden ölçülüyorsa işlem tarihindeki kurdan; yabancı para cinsinden gerçeğe uygun değerleri üzerinden ölçülüyorsa gerçeğe uygun değerin belirlendiği tarihteki spot kurdan çevrilmektedir.

Cari raporlama dönemine ait Finansal Durum Tablosundaki varlık ve yükümlülükler raporlama tarihindeki spot kurdan çevrilirken; gelir, gider ve özkaynak kalemleri işlem tarihlerindeki döviz kurlarından çevrilmektedir.

BOBİ FRS'de yer alan yabancı para çevrim işlemlerine ilişkin söz konusu hükümler TMS 21 hükümleri ile uyumludur.

\subsection{1. İș/İșletme Birleșmeleri}

BOBİ FRS'de bağlı ortaklık, iştirak ve müştereken kontrol edilen işletmelerin özkaynak yöntemi uygulanarak muhasebeleştirilmesi sırasında, TMS/TFRS'lerden farklı olarak bu işletmelerin edinim tarihindeki tanımlanabilir varlık ve yükümlülüklerini belirlemesi ve bunların gerçeğe uygun değerini tespit etmeleri gerekmemektedir. Bunun yerine iştirak ve müştereken kontrol edilen işletmelerin finansal tablolarında yer alan varlık ve yükümlülükler, yine bu tablolardaki defter değerleri üzerinden dikkate alınabilmektedir. Bununla birlikte, isteyen işletmeler edinim tarihi itibarıyla iştirak veya müştereken kontrol edilen işletmelerin finansal tablolarında yer alan varlık ve yükümlülüklerinin gerçeğe uygun değerini tespit ederek şerefiye ya da negatif şerefiye tutarını hesaplayabilir. 
BOBİ FRS'ye göre birleşme tarihi itibarıyla edinilen işletmenin finansal tablolarında yer alan varlık ve yükümlülükler, güvenilir bir şekilde ölçülebiliyorsa birleşme tarihindeki gerçeğe uygun değeri üzerinden aksi halde edinilen işletmenin birleşme tarihi itibarıyla finansal tablolarında yer alan defter değerleri üzerinden kayda alınmaktadır. TFRS 3 ise bir işletme birleşmesinde edinen işletmenin, edindiği tanımlanabilir varlıkları ve üstlenilen tanımlanabilir borçları birleşme tarihindeki gerçeğe uygun değerleri ile ölçmesini öngörmektedir.

BOBİ FRS'ye göre şerefiye tutarı; birleşme tarihinde, iş birleşmesinin maliyetinin, edinilen tarafın kayda alınan ve ölçülen net varlıklarındaki edinen işletmenin payını aşan kısmıdır. TFRS 3'e göre ise, işletme birleşmesinin maliyetiyle edinilen varlık ve yükümlülüklerin defter değeri veya gerçeğe uygun değeri arasındaki farktır.

BOBİ FRS'de işletme birleşmesiyle doğrudan bağlantılı maliyetler, işletme birleşmesi maliyetine dâhil edilmektedir. TFRS 3'te ise işletme birleşmelerinin maliyeti belirlenirken, işletme birleşmesiyle doğrudan bağlantılı maliyetler gider olarak kâr veya zarara yansitılmaktadır.

BOBİ FRS'de şerefiye değer düşüklügü testine tâbi tutulmaz ve faydalı ömrünün güvenilir bir şekilde tahmin edilemediği durumlarda 10 yılda itfa edilirken, TMS 36 uyarınca şerefiye için değer düşüklüğü testi yıllık olarak yapılmakta, şerefiye itfa edilmemektedir.

BOBİ FRS'de koşullu bedelin transfer edilen bedele dâhil edilebilmesi için koşullu bedelin oluşmasına neden olan koşul veya olayların gerçekleşmesinin muhtemel olması ve koşullu bedel tutarının güvenilir bir şekilde ölçülebilmesi gerekmektedir. TFRS 3'de ise şarta bağlı bedelin birleşme tarihindeki gerçeğe uygun değeri işletme birleşmesi için transfer edilen bedele dâhil edilmektedir.

\subsection{Konsolide Finansal Tablolar}

BOBİ FRS'de sadece büyük işletmelerin konsolide finansal tablo hazırlamaları zorunlu (diğer işletmeler ise ihtiyari olarak bu tabloları hazırlayabilmektedir) olduğu halde, TFRS 10 kapsamında bağlı ortaklığı bulunan bütün işletmelerin konsolide finansal tablo hazırlamaları zorunludur.

Diğer taraftan, BOBİ FRS'de TFRS 10'dan farklı olarak bazı bağlı ortaklıkların konsolidasyon kapsamı dişında tutulabileceği belirtilmektedir. $\mathrm{Bu}$ çerçevede $\mathrm{AB}$ Muhasebe Direktifinde yer alan hükümlerle uyumlu olarak BOBİ FRS'de, önemsiz olarak nitelendirilen bağlı ortaklıkların söz konusu olması, konsolidasyon için gerekli olan bilgilerin aşırı maliyet ve çabaya katlanmadan elde edilememesi, bağlı ortaklığın varlıkları veya yönetimi üzerindeki hakların kısıtlanmış olması veya bağlı ortaklığın bir yıl içinde elden çıkarılmasının amaçlanması durumlarında bu bağlı ortaklıkların konsolidasyon kapsamına dahil edilmemesi öngörülmektedir.

Bağlı ortaklık kıstası, hem BOBİ FRS'de hem de TFRS 10'da yatırım yapılan işletmenin ana ortaklık tarafından kontrol edip edilmediğidir.

Bağlı ortaklıkların muhasebeleştirilmesine ilişkin olarak, hem BOBİ FRS hem de TFRS 10'a göre konsolide finansal tabloların hazırlanmasında tam konsolidasyon uygulanmaktadir. 
BOBİ FRS'ye göre münferit finansal tablolarda, bağlı ortaklıklardaki, iştiraklerdeki ve müşterek girişimlerdeki yatırımlar maliyet yöntemi veya özkaynak yöntemlerinden biri tercih edilerek ölçülürken, TMS 27 uyarınca, münferit finansal tablolarda, bu yatırımlar maliyet yöntemi, gerçeğe uygun değer yöntemi veya özkaynak yöntemlerinden biri tercih edilerek, ölçülmektedir.

BOBİ FRS'de yurt dışındaki bağlı ortaklık, iştirak ve iş ortaklıklarındaki yatırımlardan kaynaklanan ve finansal tablolarda özkaynaklar altında "Yabancı Para Çevrim Farkları" kalemi içerisinde gösterilen kur farkı kazanç veya kayıpları, bağlı ortaklığın, müşterek girişimin veya iştirakin elden çıkarılması üzerine konsolide Kâr veya Zarar Tablosuna aktarılmaz, bu tutar "Geçmiş Yıllar Kârları/Zararları”na aktarılır. TMS 21'de ise söz konusu kur farkı kazanç veya kayıpları, bu yatırımların elden çıkarılması durumunda yeniden sınıflandırma düzeltmesi olarak kâr veya zarara yansitılmaktadir.

\subsection{Gelir Üzerinden Alınan Vergiler}

BOBİ FRS'de büyük işletmeler dışında kalan işletmelerin ertelenmiş vergi tutarını hesaplaması gerekmemekte; büyük işletmelerin ise ertelenmiş vergi tutarını finansal tablolarına yansıtmaları zorunlu tutulmaktadır. Oysa TMS 12 uyarınca bütün işletmelerin ertelenmiş vergi tutarlarını finansal tablolarına yansıtmaları gerekmektedir.

\subsection{Dipnotlar}

BOBİ FRS'nin 26 ncı bölümünde, finansal tablo dipnotlarının sunumuna ilişkin genel ilkeler düzenlenmekte ve diğer bölümlerde öngörülenlere ilave olarak ayrıntılı dipnot açıklamaları öngörülmektedir. Oysa TMS/TFRS'lerde dipnotlara ilişkin ayrı bir standart bulunmamakta, her standardın içerisinde dipnotlar bölümüne yer verilmektedir.

\section{SONUÇ}

Finansal tabloların gerçeğe uygun, ihtiyaca uygun ve karşılaştırılabilir sunumunu sağlamak amaciyla, 1 Ocak 2018 tarihi ve sonrasında başlayan hesap dönemlerinde uygulanmak üzere, 29 Temmuz 2017 tarihli Mükerrer Resmi Gazete' de yayımlanarak yürürlüğe giren BOBİ FRS, bağımsız denetime tabi olup TMS/TFRS'leri uygulamayan işletmelerin finansal tabloları açısından MSUGT ve "İlâve Hususlar"ın yerini alacaktır.

Uluslararası muhasebe ve finansal raporlama uygulamalariyla ve $A B$ düzenlemeleriyle uyumlu olan BOBİ FRS, işletmelerin genel olarak karşılaşabileceği tüm muhasebe işlemlerine ilişkin muhasebe esaslarını belirlemektedir. Ayrıca, kabul edilebilir bir finansal raporlama çerçevesinin gerektirdiği tüm özellikleri taşıyan BOBİ FRS, bağımsız denetime kıstas teşkil edecek "kabul edilebilir" bir finansal raporlama çerçevesidir.

TMS/TFRS ile karşılaştırıldığında BOBİ FRS'de genel olarak basitleştirilmiş muhasebe ilkelerinin yer aldığ 1 görülmektedir. TMS/TFRS'lerde gerçeğe uygun değer kullanımı yaygın olmakla birlikte, BOBİ FRS'de muhasebe uygulamalarında kolaylık sağlanması amacıyla maliyet bedeli esas alınmıştır.

BOBİ FRS'nin yayımlanmasıyla birlikte, uluslararası standartlarda kaliteli bir finansal raporlama ve bağımsız denetimin sağlanması açısından önemli bir adım atılmıştır. 


\section{Kaynakça}

6102 sayılı Türk Ticaret Kanunu, Resmi Gazete, Say1: 27846, 14.2.2011.

Doğan, Aziz, BOBİ FRS Tanıtım Toplantısı Açılış Konuşmaları, Samsun - 22.8.2017, Antalya - 5.10.2017, Konya - 11.10.2017, Kayseri - 26.10.2017.

KGK (Kamu Gözetimi Muhasebe ve Denetim Standartları Kurumu), Basın Duyurusu, http://kgk.gov.tr/Portalv2Uploads/files/Duyurular/v2/Diger/2017-2 basin duyurusu.pdf, 29.7.2017, Erişim: Kasım 2017.

KGK (Kamu Gözetimi Muhasebe ve Denetim Standartları Kurumu), BOBİ FRS Tanıtım Toplantısı sunumları, Kayseri, 26.10.2017.

KGK (Kamu Gözetimi Muhasebe ve Denetim Standartları Kurumu), Büyük ve Orta Boy İşletmeler İçin Finansal Raporlama Standardı Hakkında Tebliğ (Sıra No: 56), Resmi Gazete, Sayı: 30138 (Mükerrer), 29.7.2017.

KGK (Kamu Gözetimi Muhasebe ve Denetim Standartları Kurumu), Büyük ve Orta Boy İşletmeler İçin Finansal Raporlama Standard1, Ankara, 2017.

KGK (Kamu Gözetimi Muhasebe ve Denetim Standartları Kurumu), Görüş Talep Edilen

Özel_Hususlar,13.11.2015,http://kgk.gov.tr/Portalv2Uploads/files/Duyurular/v1/T FRS /Ek_2_Görüş Talep Edilen Özel Hususlar.pdf, Erişim: Kasım 2017.

KGK (Kamu Gözetimi Muhasebe ve Denetim Standartları Kurumu), TMS/TFRS 2017 Seti, http://kgk.gov.tr/DynamicContentDetail/6538/TMS/TFRS-2017-Seti, Erişim: Kasım 2017.

KGK (Kamu Gözetimi Muhasebe ve Denetim Standartları Kurumu), Yerel Finansal $\begin{array}{llll}\text { Raporlama Çerçevesi } & \text { Taslağı, } & \text { Kasım }\end{array}$ http://kgk.gov.tr/Portalv2Uploads/files/Duyurular/v1/TFRS/Ek_1_Yerel\%20Finan sal\%20Raporlama\%20Çerçeve\%20Taslağı.pdf, Erişim: Kasım 2017. 


\title{
A Comparison of Financial Reporting Standard for Large and Medium Sized Entities and TAS/TFRS
}

\author{
Aziz Doğan \\ Board Member, Public Oversight \\ Accounting and Auditing Standards Authority \\ Ankara, Turkey \\ orcid.org/0000-0002-6035-9379 \\ aziz_dogan@hotmail.com
}

\section{Extensive Summary}

\section{Introduction}

Financial Reporting Standard for Large and Medium Sized Entities (FRS for LMEs) was published in Official Gazette on 29 July 2017, effective for annual periods beginning on or after 1 January 2018.

FRS for LMEs establishes the accounting principles to be applied in the preparation of individual and consolidated financial statements of the entities subject to audit other than public interest entities (PIEs) implementing Turkish Accounting Standards (TAS) and Turkish Financial Reporting Standards (TFRS) and their interpretations.

The objective of this study is to examine and explain the rationale behind the issuance and the general features of FRS for LMEs issued in order to provide fair, relevant and comparable information, and make a comparison between the requirements of FRS for LMEs and TAS/TFRS.

\section{Background and Rationale for FRS for LMEs}

Public Oversight Accounting and Auditing Standards Authority of Turkey (KGK) was formed in 2011. The accounting and financial reporting requirements of new Turkish Commercial Code effective from 1 January 2013 gives mandate to KGK to issue accounting and financial reporting standards in conformity with IAS/IFRS and to set specific standards for different size entities and industries.

Under these requirements KGK decided that TAS/TFRS should be only mandatory for individual and consolidated financial statements of PIEs for periods beginning on or after 1 January 2014 (Voluntarily application of other entities is permitted.) while TAS/TFRS was mandatory for all entities subject to audit in 2013. Since the size and industries of entities subject to audit are determined by the Decree of Council of Ministers under Turkish Commercial Code, the Council of Ministers set the limit at TL 200 million net revenue, TL 150 million assets and 500 employees for 2013. As a result, entities meet two of those three criteria was subject to audit. The Council of Ministers lowered those limits in 2014, 2015 and 2016 and are expected to lower for coming years.

Since TAS/TFRS was mandatory for financial statements of PIEs for periods beginning on or after 1 January 2014, KGK decided in 2014 that other entities subject to 
audit should apply temporarily accounting principles set at General Communique on Accounting System Application (MSUGT) published by the Ministry of Finance under Tax Legislation by the time of issuance of a new standard, and started process for establishing a new local financial reporting framework (FRS for LMEs) for entities subject to audit other than PIEs by setting up a study committee composed of the representatives from public, private and professional institutions, other stakeholders, and academicians.

MSUGT applied financial statements would not be applicable financial reporting framework for the audit because of lack of valuation requirements for some items, noncompulsory application of valuation, severance pay, depreciation, rediscount requirements, and because the basic objective was tax reporting. Consequently, they got away from the objective of fair presentation, providing relevant and comparable information. Therefore, KGK temporarily issued further requirements to MSUGT in 2014.

One of the main rationale with FRS for LMEs is to make the financial statements comparable, and by that achieve a fair presentation.

On the other hand, KGK developed FRS for LMEs to meet the users' needs while balancing the costs and benefits to preparers in recognition of the difficulty and cost to entities of preparing fully compliant TAS/TFRS information. It also recognised that users of financial statements have a different focus from those interested in PIEs. Furthermore, they have no public accountability.

European Union (EU) listed entities must prepare their consolidated financial statements in accordance with IFRS. The rules non-listed entities have to follow when preparing financial statements are laid down in directive 2013/34/EU, known as the "accounting directive", effective from 1 January 2016. The objective of this directive is to harmonise national requirements.

Since EU started full membership negotiations with Turkey on 3 October 2004, Turkey should be complying with EU legislation divided into 35 chapters (the "acquis") by the time it joins EU as a full member. Accounting and Auditing subtitle under chapter 6 "Company Law" specifies rules for the presentation of annual and consolidated accounts, including simplified rules for small and medium sized entities. Therefore, the EU acquis is another rationale.

\section{General Features of FRS for LMEs}

FRS for LMEs designed to meet the needs and capabilities of Large and Medium Sized Entities (LMEs) subject to audit is a standalone standard of less than 240 pages and 27 chapters and delivers financial statements that provide useful, fair, relevant and comparable information in a simplified, consistent, cost-effective way.

On the other hand, FRS for LMEs, primarily featuring the "Think Small First" principle in EU Accounting Directive, describes the basic concepts that underlie the preparation and presentation of cost based financial statements of medium sized entities and establishes further requirements for large sized entities.

FRS for LMEs written up in a simpler and more comprehensible way compared to TAS/TFRS is in compliance with international financial reporting practices and EU regulations. In the meantime, it has all features of an applicable financial reporting 
framework for audit and sets up accounting principles. The FRS for LMEs contains simplified accounting rules for entities having no public accountability, and therefore responses all needs of them.

\section{Comparison of FRS for LMEs and TAS/TFRS}

This study is for those who wish to gain a broad understanding of the significant differences between FRS for LMEs and TAS/TFRS as well as similarities.

A selection of differences most commonly found in practice are as follows:

- While an entity shall present an analysis of expenses recognised in profit or loss using "function of expense" or "nature of expense" method according to TAS/TFRS, FRS for LMEs uses only "function of expense" method.

- There are two criteria in FRS for LMEs for recognition of revenue: when it is probable that any future economic benefit associated with the item of revenue will flow to the entity, and the amount of revenue can be measured with reliability.

- If the outcome of a construction contract can be estimated reliably, revenue and costs should be recognised in proportion to the stage of completion of contract activity according to FRS for LMEs.

- Biological assets shall be measured at their fair value or cost less costs to sell in TAS/TFRS, it shall be measured at its fair value or cost in FRS for LMEs.

- Measurement after recognition is made on either the cost model or the revaluation model for the exploration and evaluation of mineral resources assets in accordance with TAS/TFRS. FRS for LMEs uses only the cost model.

- Financial instruments are measured at amortised cost, fair value through other comprehensive income or fair value through profit or loss in TAS/TFRS while they are measured as receivables and payables, borrowing instruments, investment in an equity instrument, other financial instruments in FRS for LMEs.

- Intangible assets are amortised in five to ten years in FRS for LMEs.

- There are two broad approaches to the accounting for government grants in TAS/TFRS: the capital approach, and the income approach. The only approach in FRS for LMEs is performance model.

- Goodwill is not tested for impairment and amortized in ten years when the useful life cannot be estimated reliably in FRS for LMEs.

- It is not compulsory for medium sized entities to prepare consolidated annual financial statements in FRS for LMEs while it is compulsory for an entity that is a parent in TAS/TFRS.

\section{Conclusion}

Entities subject to audit but applying TAS/TFRS shall apply FRS for LMEs for the annual periods beginning on or after 1 January 2018.

FRS for LMEs delivers comparable financial statements that provide useful, fair, relevant information in a simplified, consistent, cost-effective way.

It is concluded that FRS for LMEs has commonly more simplified requirements even though it is similar in some ways compared to TAS/TFRS. 